REVISTA

\title{
TERRITÓRIO, DEVOÇÃO E EDUCAÇÃO EM SÃO BENEDITO: RITOS DE SOCIABILIDADE PORTOSSEGURENSE
}

\author{
TERRITORY, DEVOTION AND EDUCATION IN SAINT BENEDICT: \\ PORTOSEGURENSE SOCIETY RITES
}

\author{
${ }^{1}$ Gheisa Santos Lisboa. \\ ${ }^{2}$ Ana Cristina de Sousa. \\ ${ }^{1}$ Universidade Federal do Sul da Bahia (UFSB). E-mail: gheisa.lisboa@hotmail.com. \\ ${ }^{2}$ Universidade Federal do Sul da Bahia (UFSB). E-mail: ana_csousa@hotmail.com.
}

Artigo submetido em 16/08/2019, aceito em 14/07/2020 e publicado em 28/08/2020.

\begin{abstract}
Resumo: O artigo procura realizar uma análise sobre ritos de sociabilidade e a estruturação do território da devoção em São Benedito, o santo negro de Porto Seguro-BA. O estudo dialoga com possibilidades educacionais e decoloniais, fazendo uso da pedagogia dos objetos e se materializando em estudos sobre aspectos religiosos locais e culturais. A história da Capela, a Irmandade dos homens pretos e as relações étnico-raciais que se estabeleceram neste espaço são também objetos de reflexão.
\end{abstract}

Palavras-chave: Relações Étnico-Raciais; erritório; Pedagogia dos Objetos; Santo Negro.

Abstract: The article seeks to conduct an analysis of sociability rites and the structuring of the territory of devotion in São Benedito, the black saint of Porto Seguro-BA. The study dialogues with educational and decolonial possibilities, making use of object pedagogy and materializing in studies on local and cultural religious aspects. The history of the Chapel, the Brotherhood of Black Men and the ethnic-racial relations that have established themselves in this space are also objects of reflection.

Keywords: Ethnic-Racial Relations; Territory; Pedagogy of Objects; Santo Negro.

\section{INTRODUÇÃO}

Das narrativas sobre Porto SeguroBA, o culto e devoção a São Benedito é um dos mais antigos. Os primeiros registros datam do século XVIII, quando da chegada da primeira imagem barroca do santo negro por essas paragens, São Benedito- "o padrinho carregador", imagem que pertence atualmente à capela secular de São Benedito.
O sagrado em terras brasileiras foi disseminado no etos do catolicismo no período colonial se configurando e ressignificando ao longo do território nacional, em festejos e ritos aos santos padroeiros, "na verdade, desde os tempos coloniais, o catolicismo brasileiro traz a marca desse etos festivo. Nele tudo dá lugar à celebração" (MONTES, 1998, p. 105). 
Ao lado das celebrações católicas maiores entronizadas aos calendários litúrgicos, a devoção aos santos inseridos no que se convencionou chamar de catolicismo popular, evidenciou e categorizou grupos sociais em condições étnicas diferentes.

As associações leigas, conhecidas também como Irmandades ou ordens terceiras, criadas no bojo da sociedade escravagista e excludente, cumpriram bem o papel de construir e evidenciar o poder da Igreja católica, e separar brancos, negros, pardos, pobres e ricos sobre a égide do Santíssimo ${ }^{1}$.

Naturalizado no pensamento religioso brasileiro, os santos representantes de devoção, em sua maioria fruto da colonialidade são brancos, a exceção da mais conhecida santa Nossa Senhora Aparecida, além de São Benedito, santa Ifigênia, a Senhora do Rosário, Elesbão e alguns outros/as representantes das populações negras e pobres.

Nesta perspectiva, os monumentos religiosos que contém a capela de são Benedito, trata entre as muitas narrativas, a história de devoção a um frade negro e franciscano, São Benedito, representante de grupos étnico-raciais subalternizados, que se reconheciam e se reconhecem, em sua trajetória de solidariedade e compaixão para com os pobres e negros.

Sendo esta uma manifestação do modo de ser e viver dos portossegurenses, neste artigo apresenta-se reflexões que ajudam num exercício que se inserem ritos da sociabilidade numa perspectiva decolonial. Traz também em seu bojo, possibilidades à educadores sobre

1 O termo Santíssimo em destaque e inicial maiúscula faz menção ao Santíssimo Sacramento, a exemplo a Eucaristia, ritual da igreja católica relacionada a transubstanciação do corpo de Cristo. Tão logo, importa saber, que a menção ao Santíssimo no período colonial apresentavam em seu bojo ritos destinados em sua maioria à população branca e católica (Grifo nosso). temáticas em história local, das relações étnico-raciais em espaços de memória.

A operacionalização da pesquisa se pautou na constatação em que os ritos e manifestações sociais se dão a partir de um espaço apropriado e vivenciado pelos moradores locais e muitas das narrativas sobre a história de Porto Seguro-BA se fizeram pelos relatos orais, que se materializaram num dado território, em destaque a capela secular de São Benedito.

A apropriação desse território, que é constructo humano, atrelado às questões referentes ao poder e identidade, manifestam a territorialidade que se desloca para além da apropriação física do espaço, e se materializa, também, na cultura imaterial e subjetiva, sejam eles nos campos da ciência da religião ou educacionais.

Num processo de leitura e compreensão histórica dialoga-se com autores que versam e problematizam sobre história local, ciência e religião, como em Cavalcanti (2010), decolonialidade e pedagogia decolonial em Santos (2009), Gil e Mainerz (2017) e Candau (2010). Em leituras de documentos patrimoniais produzidos pelo IPAC-BA; em propostas curriculares, a BNCC (Base Nacional Curricular Comum, Brasil, 2016) para o ensino de história dos $7^{\circ} \mathrm{s}$ anos e suas problemáticas, e ainda, nos campos educacionais e culturais, Sílvio Gallo (2003) e Freire (2003), e outros/as autores/as.

Algumas das discussões nessa breve introdução serão dialogadas nas reflexões sobre território e controle, religião, "novos" paradigmas, histórias em São Benedito e na Irmandade dos homens pretos de Porto Seguro, além da incursão sobre conceito de decolonialidade e pedagogia do objeto contida no espaço da capela secular de São Benedito. Pretendese, portanto, discorrer sobre esses pontos, objetivando trazer à tona pesquisas sobre o santo negro, as virtudes e as 
ressignificações que as crenças em São Benedito e o patrimônio cultural que o contém criaram nas narrativas pós diaspóricas, além da adequação da temática às aulas de história.

\section{AS ORIGENS DA DEVOÇÃO A SÃO BENEDITO EM PORTO SEGURO-BA}

“[...] Meu são Benedito é santo preto

Ele bebe garapa, ele ronca no peito Meu são Benedito venho lhe pedir Pelo amor de deus pra tocar cacumbi”. Delora Bueno ${ }^{2}$

A história que permeia as construções do Parque Histórico de Porto Seguro é fruto do processo de colonização do Brasil, e não obstante está, a história da Capela de são Benedito, conhecida também como a "capela do colégio" ou ainda como "capela dos jesuítas", por se configurar a princípio e pelos estudos do Núcleo Avançado de Pesquisas Arqueológicas da Universidade Federal da Bahia (NAPAS/UFBA, 2004 apud TOFANI, 2008), de interesse inicial no estabelecimento de um antigo colégio jesuítico, e o processo de conversão às populações nativas. O geógrafo e arquiteto aborda que:

A modalidade denominada colégio ou residência, por sua vez, seria a mais conhecida dos brasileiros graças à sua tradução espacial: monumentais conjuntos arquitetônicos erigidos em vilas e cidades coloniais e consistindo em uma igreja e um edifício anexo com espaços de ensino, oficinas, armazéns, dormitórios, cozinha, claustro etc. O seu papel era servir como sede da Companhia de Jesus em um determinado território e, simbolicamente, como pólo de irradiação dos poderes e projetos divinos e seculares (TOFANI, 2008, p.349).

\footnotetext{
2 Trecho da música "Taieiras" de Delora Bueno que faz referência aos Cacumbis e devoção a são Benedito. Disponível em: HTTP://m.letras.mus.br/ delora-bueno. Acesso em: 09 de set 2019.
}

O sociólogo Roger Bastide, em seu estudo sobre a ação missionária no interior de São Paulo no período colonial assinala que as manifestações religiosas entre elas, danças, cânticos e construções desse período expressam uma forma particular de exaltação na intromissão [...] ocasionada, historicamente, pelas estratégias de catequese utilizadas pelos jesuítas e posteriormente pelos representantes da Igreja na conversão de índios e populações negras (BASTIDE, 1970, p.165-8).

Historicamente, a sociedade setecentista em Porto Seguro, até então, Capitania de Porto Seguro-BA, era composta:

[...] que por outro nome se intitula Vila de Nossa Senhora da Pena, habitava apenas o tabuleiro da Cidade Alta e era formada por europeus, indígenas e africanos, posto que quando "a gente enxergou de cima que vinham padres, toda desceu abaixo (...) e assim se encheu em breve a praia de gente branca, de índios e pretos da Guiné, e de uma nuvem de moços e meninos" (TOFANI, 2008, p. 338).

Nesse caso e a partir da historiografia local, sabe-se que o ciclo econômico obedeceu ao capital mercantil, cuja mão-de-obra escrava foi determinante para a economia nacional, não somente enquanto mãos que trabalhavam, mas participantes do processo produtivo "é factível que uma boa parte da mão-de-obra empregada fosse constituída por escravos africanos"(TOFANI, 2008, p. 344).

Seguindo na história da capela de são Benedito se faz importante ressaltar que materialidade e imaterialidade deste espaço compõe hoje uma das inúmeras possibilidades de pesquisas, para além do fazer acadêmico. Vale lembrar que a conotação do Patrimônio transcende o aspecto monumental, sendo, portanto, alicerce de identidade e memória.

O patrimônio é o legado que recebemos do passado, vivemos no presente e transmitimos às futuras gerações. Nosso patrimônio cultural é 
natural é fonte insubstituível de vida e inspiração, nossa pedra de toque, nosso ponto de referência, nossa identidade (ORGANIZAÇÃO DAS NAÇÕES UNIDAS, s.p. 1972).

De acordo com estudos históricos e informações turísticas instaladas dentro do Parque Histórico de Porto Seguro-BA, a capela foi construída no século XVI, e faz parte do antigo Colégio Residência de Salvador, a primeira escola para meninos. O colégio funcionou até 1759 , quando os jesuítas foram expulsos do Brasil. Foi usada também como moradia de um professor de latim até 1820. A capela resistiu até 1917, quando foram retirados materiais da estrutura para se construir uma serraria. A partir de 1973, quando do tombamento do Parque pelo então SPHAN (Serviço do Patrimônio Histórico e Artístico Nacional) atualmente IPHAN (Instituto do Patrimônio Histórico e Artístico Nacional) a salvaguarda desse patrimônio material foi retomada, o que lhe deu as características descritas nas imagens das figuras 1 e 2 .

Figura 1: Igreja de São Benedito.

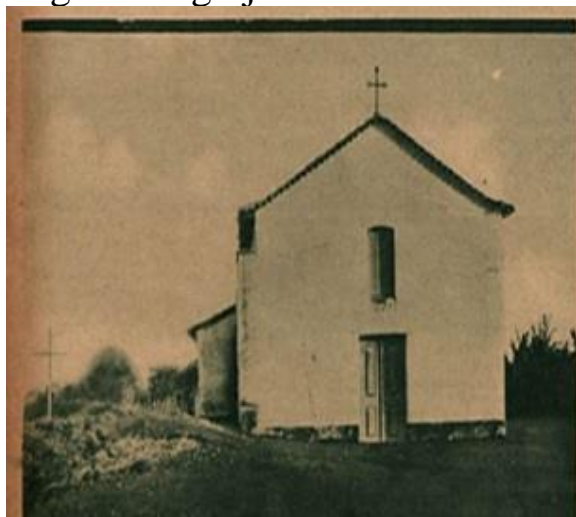

Fonte: Revista O Cruzeiro.

O recorte da reportagem da Revista O Cruzeiro (RJ), de 1938, Ed. 28, traz a Capela de São Benedito, naquela época mais conhecida como Igreja dos jesuítas. Matéria de capa intitulada "Revoada a Porto Seguro" aborda a chegada de pilotos ao município de Porto Seguro-BA.

Figura 2: Igreja de São Benedito e, à sua esquerda, as ruínas da Residência do
Salvador, na Cidade Alta de Porto Seguro. Observações às alterações na fachada nas duas imagens quando da reforma pelo SPHAN.

Figura 2: Igreja de São Benedito.

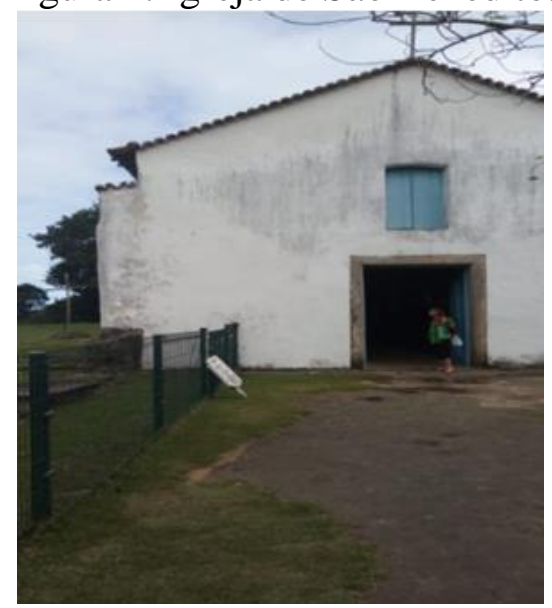

Fonte: Acervo pessoal da autora.

A figura mostra a Igreja de São Benedito e, à sua esquerda, as ruínas da Residência do Salvador, na Cidade Alta de Porto Seguro. É possível observar as alterações na fachada nas duas imagens quando da reforma pelo SPHAN.

Sua localização na atual Rua Dr. Antônio Ricaldi, no centro histórico, localizado na cidade alta, recebe visitantes, estudantes, professores, guias e comunidade local, e guarda em seu interior uma das três imagens de São Benedito, "O Padrinho Carregador", e duas de São Benedito das Flores, se encontram atualmente no Museu de Arte Sacra, antiga Igreja da Misericórdia, além dos ex-votos, que se materializam a partir dos pedidos de fé feitos ao santo negro, fotografias e antigas imagens da capela e dos festejos católicos .

Essas imagens não foram feitas ao acaso, construídas em barro, madeira e marfim, em estilo barroco, reforça a atuação e presença da Irmandade de são Benedito dos homens pretos de Porto Seguro, que funcionou no município do século XVIII até meados de 1970. 
Figura 3: Semanário do jornal Correio de Porto Seguro de 1914

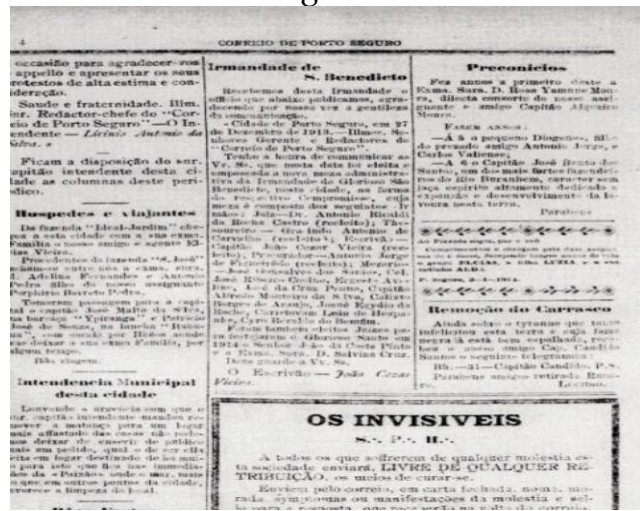

Fonte: disponível em: http://memoria.bn.br /pdf/218103/per218103_1914_00093.pdf. Acesso em 01/08/2019.

O Semanário do jornal Correio de Porto Seguro de 1914, acima, comunica nova mesa administrativa da Irmandade de São Benedito na cidade de Porto SeguroBA. A história de devoção a São Benedito se insere numa valorosa fonte histórica, uma vez que as imagens contidas no Museu de Arte Sacra e na capela relembram a história de um santo negro. Filho de um casal de africanos, descendentes de escravos, que foram trazidos para a Sicília e convertidos ao catolicismo, aos 18 anos de idade entrou na Ordem Terceira de São Francisco e passou a viver no Convento de Santa Maria de Jesus, em Palermo. Nesse local, desempenhou a função de cozinheiro e, apesar de ser analfabeto e negro, mais tarde torna-se Frei superior dos noviços. Três séculos após sua morte foi canonizado em 24 de maio de 1807, devido a comprovação de inúmeros milagres de fé.

Ao bom e milagroso santo tantas histórias foram destinadas que caberiam em muitos outros estudos sobre sua religiosidade. Há registros de curas a cancerosos, milagre de flores, multiplicação de peixes e pães, afinal, São Benedito também é conhecido como o santo dos cozinheiros e todos que trabalham na cozinha, carinhosamente apelidado por seus devotos como "açúcar mascavo", pela cor e docilidade. Das muitas histórias sobre São Benedito uma é replicada sempre quando a hagiografia (estudo biográfico do santo) é requisitada, a saber: conta-se que sempre que podia são Benedito "apanhava" alguns alimentos do convento que residia e colocava nas dobras de sua roupa, para dispor aos necessitados. Em certa ocasião surpreendido por seu superior que ao lhe indagar sobre o que carregava nas dobraduras, São Benedito lhe respondera que eram Rosas, sendo desacreditado pelo então senhor que lhe fez mostrar os alimentos suspeitados, e em seu lugar o que surgiu foi uma braçada de rosas cheirosas.

São inúmeras as narrativas e histórias, mas o fato é que o culto local a são Benedito, interiorizado nas devoções santeiras do catolicismo popular, conserva todos os anos a tradicional puxada do mastro, que apresenta hasteada a bandeira do Santo no ponto alto, as missas, novenas e procissões, como a "Esmola de São Benedito" com os cacumbis que ocorrem nos dias 05/10 em Porto Seguro e 27/12 em Arraial D'Ajuda, e faz um trajeto que se inicia na "igreja do colégio", capela de são Benedito. Portanto, a devoção a são Benedito em Porto Seguro-BA, os exvotos, a procissão, comprova a "contribuição da população negra na formação da sociedade portossegurense" 3 .

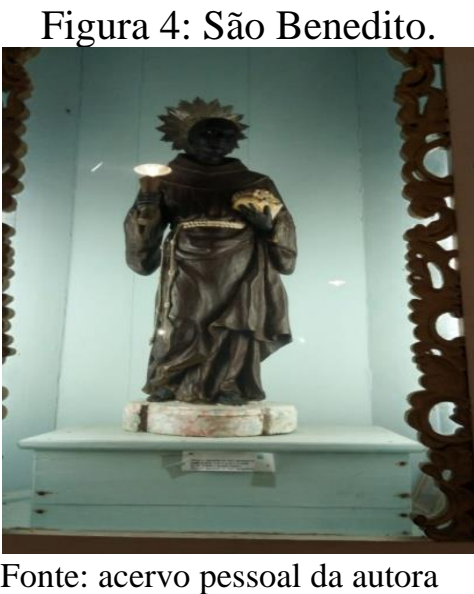

\footnotetext{
3 Trecho de matéria publicada no site Radar64 "Exposição reconta a história da devoção ao São Benedito em Porto Seguro" em 11/03/2019. Disponível em: https://radar64.com/noticia/ exposicao-reconta-historia-da-devocao-aosaobenedito_40922.html.
} 


\section{SÃO BENEDITO EM PORTO SEGURO-BA: CONTROLE E REGULAÇÃO DO TERRITÓRIO}

Dos estudos em religião e religiosidade, parte uma categoria que merece análise para discussões em vários campos de saberes e ultrapassa a ciência geográfica e natural, que é o conceito de território. Sobre território entende-se um espaço físico onde ocorre apropriação e o uso do poder entre os homens e o ambiente que o circunda. No entanto, é preciso pensar essa categoria em outros campos de pensamento, uma vez que essa apropriação também desloca-se sobre a subjetividades, afetividades, sentimentos, entre outros/as.

Reconhece-se que nos tempos coloniais no Brasil a Igreja católica se territorializava plenamente na vida pública e privada dos sujeitos, e primava por exercer $o$ poder sobre várias esferas sociais, legitimado pela forte interferência no Estado. A igreja "foi igualmente capaz de acomodar-se ao etos da sociedade em que se inseria e assim incorporar sistemas de crenças particularistas e locais" (MONTES, 1998, p. 101).

\section{A historiadora Maria Wissenbach} (1998) dialoga sobre as crenças e particularidades das festas destinadas aos santos:

Originadas das devoções particulares e dos compromissos mantidos com os santos nas fainas diárias, as festas de santos pontuavam um momento em que as graças recebidas seriam contempladas e as promessas cumpridas, marcando as relações intergrupais (WISSENBACH, 1998, p. 82).

Entendendo que "a religião é um conjunto de símbolos capazes de redefinir o mundo" (SIQUEIRA, 2010, p.151), a história da religião no Brasil se mistura a presença da Igreja católica, desde os tempos coloniais, ou pelo menos "reduz e neutraliza todas as diferenças na igualdade simbolizada na norma branca" (MUDIMBE, 2013, p.24), tendo, portanto, um campo fértil para poderosos agenciamentos (CARNEIRO, 2005) e relações de poder, cuja gama de discursos, se encerra numa prática de ritual que determina aos sujeitos que falam propriedades pré-estabelecidas e legitimação de poder, ancorada em crenças particulares e locais (FOUCAULT, 2003).

No campo de estudo sobre a religiosidade popular, o catolicismo ganhou força a partir da conquista e colonização, sobretudo, se ramificou para além do rigor romano, pois se misturou a outros credos e procedências locais. Foi a partir dessa dinâmica, que diferentes lugares e espaços de devoção e seus oragos, capelas, santuários, ermidas de estrada, irmandades foram se territorializando em espaços de discursos para leigos.

Em arquivos eclesiásticos do século XVII, como das Constituições do Arcebispado da Bahia, D. Sebastião Monteiro da Vide, o então arcebispo da Bahia, declarou em Livro Primeiro (1853):

Tít. 2. Como são obrigados os pais, mestres, amos e Senhores a ensinar, ou fazer ensinar a Doutrina Christã aos filhos, discipulos, criados e escravos. [...]

Tít. 5. Como os leigos não devem disputar sobre materias de nossa fé. [...]

Tít. 8. Do culto devido ás Santas Relíquias, e sagradas imagens. [...]

Tít. 25. Como os leigos ${ }^{4}$, e Sacerdotes, que não celebram, só devem receber o Santissimo Sacramento na especie de pão; e que aos condenados pela justiça se lhe administre um dia antes de morrer. $[\ldots]$

\footnotetext{
${ }^{4}$ Leigos para a Igreja Católica são os membros que não são ordenados, isto é que não receberam o sacramento da ordem. Os que recebem o sacramento da ordem são os bispos, os sacerdotes (presbíteros), e os diáconos. Incluindo-se nesses grupos os que não sendo ordenados, são membros de ordens e congregações religiosas, habitualmente designadas por irmãos, frades, irmãs, freiras (Grifo nosso).
} 
Tít. 56. Das matriculas, e cartas de Ordens. [...]

Tít. 59. Como são applicados os clérigos de Ordens Menores ao serviço de alguma Igreja. ${ }^{5}$

O documento eclesiástico aplicou

bem o dogmatismo romano pelas paragens baianas. Observa-se que a "pedagogia religiosa" caracterizou-se em manter o domínio da Santa fé católica e tornar necessário o ingresso de ordens ou corporações de leigos para manutenção do status quo religioso, amparados em assistência material e espiritual para os que aderiam e correspondiam as exigências determinadas pela madre igreja.

A especialista em história das Irmandades Mineiras e mestre em História Social, Sant'Anna (2010, p.130) aborda a temática explicando que as associações religiosas, conhecidas como ordens terceiras ou irmandades leigas, "primavam pelas obras pio-caritativas e pela prestação de serviços funerários".

Há relatos orais e registros em veículos de comunicação de Porto Seguro (Fig. 3) entre o final do século XIX e início do XX, que na constituição da história de devoção em São Benedito esteve também refletida a Irmandade dos homens pretos de Porto Seguro. A ideia do culto ao santo negro, revela que o pertencimento à determinado grupo e os compromissos firmados entre os integrantes marcavam relações de sociabilidade dando-lhes identidade. No entanto, cabe uma crítica da historicidade sobre os santos negros, cujo a simbologia revela que a Igreja católica se apropriou desses oragos para catequização dos escravizados.

\footnotetext{
5 Transcrição de Arquivos Eclesiásticos do século XVII, de alguns dos títulos que se contém no livro primeiro das Constituições do Arcebispo da Bahia, D. Sebastião Monteiro da Vide. São Paulo. Typographia, 2 de dezembro de 1853 . Antonio Louzada Antunes, p. 3 a 246. A escolha dos títulos faz uma breve referência ao objeto de estudo em análise.
}

O candidato a integrar a irmandade tinha que se adequar a alguns termos e normas de conduta estabelecido por documentos chamados de Compromissos, muito parecidos em todas as Irmandades que se estabeleceram ao longo do território nacional. A exemplo a trancrição de um artigo deste documento em Irmandade de São Benedito em:

São Irmãos da Irmandade de São
Benedicto todos aquelles que
voluntariamente se queiram alistar,
uma vez que professem a Religião
Catholica Apostolica Romana, sem
distincção de sexo, estado ou
qualidade; que não tenham crimes ou
vícios, que os tornem despreziveis
aos olhos do publico; que não estejam
filiados á alguma das seitas
condemnanas pela Igreja Catholica; e
que se obriguem a cumprir os ônus e
mais obrigações deste compromisso
(COMPROMISSO..., 1897 apud
MENDES, 2011, p. 91).

Observa-se que assim como o documento do Arcebispo da Bahia de 1853 e o artigo do compromisso de 1897, para se filiar a irmandade era necessário obedecer a critérios, depositados no caráter católico de organização não aceitando pessoas "filiados á alguma das seitas condemnanas pela Igreja Catholica”. Sendo este um território autônomo, a Irmandade era uma maneira também de vigilância que a Igreja e o poder eclesiástico poderiam impor aos seus participantes, entre os quais negros, pardos, mestiços em geral, sendo estes parcelas pobres, uma vez que "as irmandades formadas por africanos eram sempre as mais suspeitas de heresias" (MENDES, 2011, p.92).

Havia outras formas de controle como a presença constante de um pároco nas reuniões da mesa, o que em todo Brasil parecia ser uma prática e norma às Irmandades, já que constam seus nomes em atas. Outro aspecto relevante do documento é a distinção dos participantes, não sendo, portanto, permitido "crimes ou 
vícios, que os tornem desprezíveis aos olhos do publico".

$\mathrm{Na}$ raiz do diálogo até aqui proferido, o que está em observância é uma conduta que obedecia a disciplina, cabendo a ordem aplicar e julgar penas aos infratores, "a boa conduta, assentada nos princípios cristãos, deveria ser espelhada na vida do orago que cultuavam, tendo como propósito edificar os demais fiéis católicos" (MENDES, 2011, p.92), há uma "ontologia histórica de nós mesmos nas relações de poder que nos constituem como sujeitos atuando sobre os demais" (VEIGA, 2003, p.56).

Apesar dos códigos disciplinadores dentro das Irmandades havia interesses particulares em pertencer a uma ordem terceira, ora pela participação, ora pelos laços de solidariedade que se manifestavam nos espaços inseridos. Um caráter importante, a saber, é que, elas constituíram veículos importantes de reconhecimento aos sujeitos envolvidos, era uma referência social e religiosa.

Nora (1993) em "Entre memória e história: a problemática dos lugares" alerta sobre o quanto a História é uma reconstrução sempre problemática e incompleta do que não existe mais, tão logo, historicizar os mais de três séculos de escravismo no Brasil não é tarefa fácil, é acima de tudo problematizar sobre "a história da história" (NORA, 1993).

Ademais, para um cativo pertencer a uma ordem era a possibilidade de participar dos festejos, procissões e romarias, mesmo que sobre a tutela do estado e da igreja, era a possibilidade de ter comprada sua carta de alforria, ou poder ser enterrado com as honras dos rituais carregados de simbolismo, mesmo sem as honrarias dadas as demais classes. Por sua grande influência "entre as devoções santeiras do catolicismo popular, São Benedito desfrutava lugar de destaque dos egressos da escravidão" (WISSENBACH, 1998, p. 81).
$\mathrm{O}$ pertencimento à irmandade, no entanto, significava que o irmão, ao falecer, teria um enterro digno e cristão, que seria acompanhado pelos membros da irmandade à sepultura, vestidos com suas opas e carregando tochas acesas, que sua alma receberia preces e orações, conforme determinavam os artigos referentes às missas e sepultamentos (MENDES, 2011, p.95-6).

Figura 5: Oração em forma de Cruz, anos de 1940- "Glorioso São Benedito, bem aventurado (...) contra malefícios e feitiçarias e as tentações do pecado, escudo contra os inimigos e mordidas de cão danado, contra os mal intencionados".

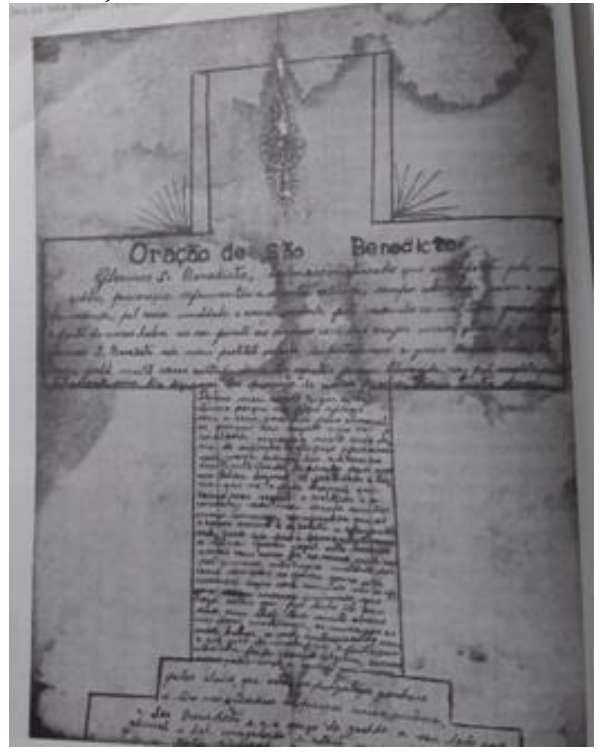

Fonte:(WISSENBACH, 1998, p. 80).

$\mathrm{Na}$ transcrição acima o autor importa uma reflexão sobre um dos inúmeros pontos referendados nos compromissos das Irmandades, que em geral no Brasil tinham características muito próximas. Tais demandas destinadas ao mundo dos mortos dialogam com o mundo dos vivos, pois é na hora "derradeira" que os ritos de sociabilidade mais aparecem. Pensar sobre os funerais destinados às populações em geral, entre os quais os negros é imaginar que na despedida física pairam o peso das diferenças nas relações entre poder e resistências, uma vez que a eles fora de qualquer instituição não se era possível os ritos de passagem católicos. 


\section{4 "NOVOS" PARADIGMAS E EPISTEMOLOGIA EM SÃO BENEDITO}

Pensando num campo de discursos que surgem a partir das ciências sociais e nas relações de poder impressas no campo das religiões e religiosidades, a análise de Foucault (2003), faz uma indelével relação entre as narrativas e as construções pensadas de maneira universalizantes, estando os sujeitos inseridos em uma "sociedade de discurso" e amarrados a papéis predeterminados.

Os discursos religiosos, judiciários, terapêuticos e, em parte também, políticos não podem ser dissociados dessa prática de um ritual que determina para os sujeitos que falam, ao mesmo tempo, propriedades singulares e papéis preestabelecidos (FOUCAULT, 2003, p.39).

Os modelos de ciência e o estudo das religiões abordados por Cavalcanti, historiador e especialista em história da Religião e História da Inquisição (2010, p.180) informa que "Encarar cientificamente as religiões é um desafio duplamente vivenciado pela onipresença do tema no cotidiano de todos nós, o que torna a objetividade científica um desafio indispensável".

Daí parte o único a priori (VEIGANETO, 2003) da História: o de se basear no conhecimento do passado para se insurgir contra o presente, sem elementos totalizantes, sem teorias e narrativas com explicações gerais da história.

Nesse dilema de se desconstruir uma história totalizante e em se tratando de um método científico para se explicar a religião e o sagrado, há um paradoxo ainda maior, um "novo" paradigma em que "no caso das religiões como objeto de estudo, o cientificismo, tem um alcance curto que torna o saber tantas vezes um apanhado de fantasias travestidas de conceitos" (CAVALCANTI, 2010, p.182). A plausibilidade se firma a partir do paradigma dominante (o velho) e o emergente (o novo), posto que, como afirma Sousa Santos, "para o velho paradigma, a ciência é uma prática social muito específica e privilegiada porque produz a única forma de conhecimento válido" (SANTOS, 2013, p. 328). E ainda, sob a égide do "novo":

\section{O novo paradigma constitui uma alternativa a cada um destes traços. Em primeiro lugar, nos seus termos não há uma única forma de conhecimento válido. Há muitas formas de conhecimento, tantas quantas as práticas sociais que as geram e as sustentam (SANTOS, 2013, p. 342)}

Dessa análise, faz-se necessário que a ciência em sua objetividade e investigação analítica se proponha a aceitar e debater assuntos e temáticas que partam do imaginário, que converse com outros conhecimentos, que (re)crie "admitir a origem transcendente/religiosa dos nossos mais caros valores políticos e éticos. Toda ética, afinal, é transcendente" (CAVALCANTI, 2010, p.189), cabendo em todo campo do conhecimento defenderse das tão caras certezas.

Em se tratando de um método científico e estudos sobre o uso de imagens sagradas, que surgem na esfera da colonialidade, que no Brasil permanece há mais de quatro séculos, a devoção em São Benedito, assim como em outros santos já representava desde o período colonial um interesse em novas perspectivas em arte figurativa e "em criar ordenações de saber aplicadas a um discurso de verdade, não somente, na forma, porém relativo a grandes e poderosas imagens do Estado e da Igreja" (MELLO, 2010, p.195).

Por essa razão, se faz necessário uma crítica sobre o discurso de verdade pautado nas esferas do Estado e da Igreja. Santos (2013) chamou de epistemicídio ao movimento que os discursos de verdade elencam ao conteúdo a ser instituído e ensinado, a maneira como atravessa e se instala no processo histórico hegemônico, apagando e subjugando saberes. 
Historicamente o colonialismo e a colonização do Brasil, que se estabeleceu com a expansão europeia e catequização, a partir da educação jesuítica, não só subjugou e genocidou povos "extraeuropeu", "como marginalizou e ilegalizou práticas e discursos sociais que podiam constituir ameaças à expansão capitalista" (SANTOS, 2013, p. 343).

Na sua adaptação às particularidades
da sociedade brasileira, o
epistemicídio terá sua primeira
expressão, enquanto tentativa de
supressão do conhecimento nos
processos de controle, censura e
condenação da disseminação de
idéias empreendido pela Igreja
Católica durante o vasto período da
história do Brasil com
desdobramentos específicos sobre a
população negra (CARNEIRO, 2005,
p. 102).

A autora adverte sobre aspectos de historicidade e epistemicídio, importantes conceitos para compreensão dos modelos epistemológicos dominantes. Pautando-se em "novos" paradigmas que desestabilizam o $\quad E u$ hegemônico (CARNEIRO, 2005), abrem-se linhas de fuga, insurreição dos saberes (FOUCAULT, 2002), novas análises sobre as ciências humanas, que em geral, e em sua ingerência cumpriram ao longo do tempo, seu péssimo papel de invenção do outro, a partir de estereótipos, e préconceitos.

Parafraseando "insurreição de saberes" em Foucault (2003), os conflitos e modelos de confronto que se darão dentro dos novos estudos das ciências sociais trazem para o campo educacional novos desafios para escola, professores, análise de currículo e formação docente, que rompem epistemologicamente com modelos que naturalizaram as diferenças culturais entre os sujeitos por meio de sua codificação com a ideia de raça; entender a (re)localização temporal das diferenças, de modo que tudo aquilo que é não-europeu é percebido como passado (QUIJANO, 2005).

\section{DECOLONIALISMO EM SÃO BENEDITO: UM OLHAR SOBRE SEUS OBJETOS}

\author{
...há que se reverenciar e defender \\ especialmente as capelinhas toscas, \\ as velhices de um tempo de luta e os \\ restos de luxo esburacado que o \\ acaso se esqueceu de destruir.
}

(Mário de Andrade)

No início de 2019 foi inaugurada uma exposição na Capela secular de São Benedito, cuja temática se pautou na história da devoção ao santo negro de Porto Seguro-BA. Com o apoio de algumas entidades locais, o acervo que contém hagiografia (estudo biográfico sobre o santo), fotografias de antigos festejos e as três imagens do santo foram expostos.

Sem dúvida ninguém vai a uma exposição dentro de um museu de arte sacra ou em uma capela seiscentista para visualizar tão somente os santos de madeira ou as construções arquitetônicas. Há sem dúvidas um interesse além, que transita entre a materialidade dos objetos presentes e as memórias das celebrações que se deram neste espaço. As subjetividades dentro de um pedido nos ex-votos, os caminhos para as romarias, entre outros. "Se aprendemos a ler palavras, é preciso exercitar o ato de ler objetos, de observar a história que há na materialidade das coisas" (RAMOS, 2004).

Vem daí a necessidade da reflexão que, partindo do contexto cultural, questione o que há de importante nesse ou naquele objeto em particular, uma leitura que deve se basear num entendimento que"cultura para nós, insisto, são todas as manifestações humanas, inclusive a cotidianidade, e fundamentalmente na cotidianidade está à descoberta do diferente, que é essencial" (FREIRE, 1985, p.17).

Dessa concepção de objeto e cultura, a pergunta que deve surgir a partir de uma micro análise, em geral, denota a 
participação dos sujeitos históricos. Para tanto, a possibilidade de ensino dentro da capela de são Benedito, como um espaço privilegiado de resgate e informação aos professores, alunos, comunidade local, ultrapassa e reitera o protagonismo de agentes sociais dentro dessas esferas nas relações étnico-raciais que se territorializaram nesse lugar de memória.

No campo educacional o enfoque e parte circunstancial contido na Lei de Diretrizes e Bases trazem em sua prerrogativa sobre educação das relações étnico-raciais a inclusão nos currículos escolares, a luta dos povos negros no Brasil, além da cultura que inclui os costumes diversos dos negros na formação da sociedade nacional.

Desenvolver ações e estratégias no âmbito da política de formação de professores (as), a fim de proporcionar o conhecimento e a valorização da história dos povos africanos, da cultura afro-brasileira e da diversidade na construção histórica e cultural do país e promover o desenvolvimento de pesquisas e produção de materiais didáticos e paradidáticos que valorizem, nacional e regionalmente, a cultura afro-brasileira e a diversidade (BRASIL, 2013, p.19).

Partindo de uma análise dos currículos escolares e sobre a temática da valorização da cultura brasileira, a Base Nacional Curricular Comum (BNCC, 2016), já em curso para as séries finais, propõe para o Ensino de História:

A valorização da história da África e das culturas afro-brasileira e indígena (Lei $\mathrm{n}^{\circ} 10.639 / 2003$ e Lei $\mathrm{n}^{\mathbf{0}}$ 11.645/2008) ganha realce não apenas em razão do tema da escravidão, mas, especialmente, por se levar em conta a história e os saberes produzidos por essas populações ao longo de sua duração. Ao mesmo tempo, são objetos de conhecimento os processos de inclusão/exclusão dessas populações nas recém-formadas nações do Brasil e da América ao longo dos séculos
XIX e XX (BRASIL, p. 414-415, 2016).

Um exemplo a ser citado são os conteúdos da Educação Básica a serem trabalhados no $7^{\circ}$ ano ( $6^{\mathrm{a}}$ série) tratados pelo Ministério da Educação em Unidades Temáticas: "No $7^{\circ}$ ano, as conexões entre Europa, América e África são ampliadas. São debatidos aspectos políticos, sociais, econômicos e culturais ocorridos a partir do final do século XV até o final do século XVIII" (BRASIL, 2016, p. 416).

Das quatro unidades temáticas a serem discutidas ao longo do $7^{\circ}$ ano propostas pela $\mathrm{BNCC}$, vários objetos de conhecimento serão trabalhados, e em três delas abordam e discutem conexões entre a modernidade e as sociedades africanas, americanas e europeias, as organizações do poder, e lógicas comerciais e mercantis na modernidade, em "A estruturação dos vicereinos nas Américas/ Resistências indígenas, invasões e expansão da América Portuguesa/ A escravidão moderna e o tráfico de escravizados" (BRASIL, 2016, p. 420/objetos do conhecimento).

É preciso, contudo, problematizar nesses quadros que a BNCC (2016) apresenta e impõe dentro das unidades temáticas, alguns pontos que reforça $o$ modelo normativo macropolítico, por exemplo, a temática "invasões e expansão da América Portuguesa", que retrata sem problematizar uma história que só existe a partir da chegada dos portugueses, sendo assim, "o fato é que os currículos escolares continuam sendo estruturados e praticados sob o julgo das disciplinas, das normatizações, do controle e da regulação" (BRITO, 2019).

Faz-se necessário problematizar ainda, que a articulação e normatização do currículo se faz muito mais pela política de compensação, do que na salvaguarda para a autonomia do sujeito. Sobre esse aspecto a educadora Brito (2018) aborda:

$$
\begin{array}{lrr}
\text { Cabe destacar } & \text { que ao } & \text { estabelecer } \\
\text { correlações } & \text { entre } & \text { diversidade } \\
\text { sociocultural } & \text { e } & \text { fatores }
\end{array}
$$


socioeconômicos, todo um conjunto de estratégias neoliberais, assentado na ideia da privação cultural e econômica, é naturalizado. Este tipo de lógica discursiva produz muito mais políticas compensatórias (estudantes culturalmente carentes) do que práticas descolonizadoras das relações sociais que atravessam e corporificam os cotidianos escolares (BRITO, 2018, p.1019)

Nas palavras do filósofo Gallo (2003), que em seu livro "Deleuze \& a Educação fez uma leitura de alguns dos conceitos pensados pelo filósofo Gilles Deleuze:

Se a educação maior é produzida na macropolítica, nos gabinetes, expressa nos documentos, a educação menor está no âmbito da micropolítica, na sala de aula, expressa nas ações cotidianas de cada um (GALLO, 2003, p.65).

Cabe sem exaustão, que a experiência na sala de aula apresente discussões e insurgências, posto que a escola é um lugar criativo, de permanências, mas também de transformações. Ao professor militante (GALLO, 2003) cabe a construção coletiva e possibilidades de novas abordagens, que não se encerre sob seu ponto de vista.

Em se ressaltar a possibilidade de aprendizado a partir das brechas, fissuras sobre o currículo, na "desterritorialização das diretrizes da educação maior" (Gallo, 2003, p. 67), em ponderar "toda educação como ato político" (Gallo, 2003, p. 67), e pensando em uma "educação menor" (Gallo, 2003), espera-se que a escola seja lócus que resista, que se entrincheire a educação maior, imposta e normativa. Como bem salienta Sueli Carneiro (2005, p.10), parafraseando Foucault, "campo das resistências que, qualquer dispositivo de poder produz".

Tomando como base uma educação ancorada nas micro-relações, nos atos cotidianos e locais, "uma política do cotidiano, das relações diretas entre os indivíduos, que por sua vez exercem efeitos sobre as macro-relações sociais" (Gallo, 2003, p.68), toma-se a exemplo do diálogo proposto neste intertítulo, uma conversa sobre decolonialismo de duas autoras que versam sobre decolonização em espaços de memória e o protagonismo das relações étnico-raciais para desestabilizar a colonialidade:

\section{Se seguimos na argumentação que, para estudar, pensar e tratar da decolonização dos espaços de memória é igualmente necessário tratar do cotidiano e dos sujeitos sociais envolvidos nas relações que ali destacamos, urge evidenciar que esses espaços sejam pensados em relação direta com os intelectuais e movimentos sociais indígenas e negros. O protagonismo desses grupos é fundamental para que se desestabilize a colonialidade do poder e do saber. (GIL; MEINERZ, 2017, p.25)}

Para as autoras há uma necessidade em se tratar as relações sociais em espaços de memória, que guardam em seu interior o protagonismo insurgente e reativo sobre as categorias normativas. A exemplo, as fontes históricas como sítios históricos, núcleos urbanos, museus, capelas, a imaterialidade em manifestações religiosas, danças e folguedos guardam instâncias de controle que interferem nas formações reais, "há sobretudo, nos objetos um ponto de ataque, de perspectiva, delimitação e interdições" (FOUCAULT, 2003, p.49).

\section{Contextualizando com as} discussões até aqui proferidas, um questionamento surge: como a partir desses objetos e a história contida neles, pode-se fazer uma pedagogia decolonial e que desterritorialize a "educação maior"?.

Muito mais importante do que dar respostas a essa pergunta é pensar um pouco sobre os fatores condicionantes, os fatores geradores de uma história que se pautou numa produção de conhecimento regulado na visão eurocêntrica, deserdando e colocando a margem as "epistemologias 
da periferia ocidente" (CANDAU, 2010, p.17).

Partindo então de uma análise decolonial é possível pensar a educação como um motor de lutas contra a colonialidade, a partir das ações sociais, a partir das pessoas, das suas práticas cotidianas e políticas, a partir de propostas pedagógicas que protagonizem as relações étnico-raciais em espaços marginalizados.

Nesta perspectiva a proposta $\mathrm{e}$ objeto deste estudo se faz possível e se materializa a partir da análise e territorialização da memória e devoção em são Benedito. Numa aula de história sobre o Brasil Colonial é possível trabalhar em turmas de $7^{\circ}$ ano ( $6^{\mathrm{a}}$ série) da Educação Básica, aspectos do cotidiano da sociedade do século XVIII, no Brasil, dos quais se aborda a presença maciça e religiosa, sobretudo a partir das associações e sociedades leigas mineiras, fazendo uma análise em torno da Irmandade dos homens pretos, presente na devoção em são Benedito e relações de sociabilidade portossegurense, além de histórias em narrativas locais.

\section{CONCLUSÕES}

O texto dedicou-se a analisar o processo de estruturação e territorialização da devoção em são Benedito, em vias de se compreender ritos de sociabilidade portossegurense. Para tanto utilizou como lócus a capela secular localizada no Parque Histórico, análise sobre um breve histórico da devoção ao orago, discussões sobre a Irmandade dos homens pretos de Porto Seguro-BA, e possibilidades educacionais e decoloniais para as aulas de história.

Algumas das imagens e documentos consultados dialogaram com o objeto de estudo a fim de se compreender as manifestações do sagrado, atrelados as formas de reconhecimento e pertencimento a uma ordem, irmandade ou outra forma de devoção mais intimista. Vale ressaltar que o material contido revela valorosa fonte material e imaterial, além de possibilitar uma análise sobre de que maneira pertencer a um determinado território dá sentido e seguridade a ações cotidianas sejam elas afetivas, espirituais e educacionais.

À luz das iniciativas de conhecimento e preservação dos sítios históricos e patrimônios culturais e da importância ao direito à memória, a abordagem do atual estudo se traduz, na relevância de que todos são sujeitos históricos em potencial e circunstancialmente, tem direito aos bens materiais e imateriais, representativos da cultura e da história brasileira.

Para tanto, no exercício da cidadania deve-se ter direito ao passado, da mesma forma que se deve ter responsabilidade em garanti-lo, problematizando sobre as permanências e transformações, dialogando sobre as diferenças culturais, permitindo que e em acessos, se permita ao novo, discutindo a questão do racismo epistêmico (CANDAU, 2010), que considera os conhecimentos não-ocidentais como inferiores.

Numa abordagem crítica sobre fronteiras, busca-se a partir de uma pedagogia decolonial em são Benedito, retratar a história colonial em vias de reconhecimento da população negra, com o protagonismo que lhe encerra, na constituição e na construção de uma genuína história nacional.

\section{AGRADECIMENTOS}

Aos docentes, em especial a Eliana Póvoas, e discentes do Programa de PósGraduação em Ensino e Relações Étnicoraciais (PPGER) da Universidade Federal do Sul da Bahia (UFSB), do qual fazem parte as autoras Gheisa Santos Lisboa (mestranda), Ana Cristina de Sousa (orientadora). 


\section{REFERÊNCIAS}

ASSIS, Angelo Adriano Faria de; PEREIRA, Mabel Salgado et al. Religiões e religiosidades: entre a tradição e a modernidade. São Paulo. Paulinas, 2010.

BASTIDE, Roger. Le prochain et le lointain. Paris, Éditions Cozas, 1970.

BRASIL. Ministério da Educação. Base Nacional Curricular Comum. Disponível em:http://basenacionalcomum.mec.gov. br, 2016. Acesso em: 23/03/2019.

BRASIL. Lei de Diretrizes e Bases da Educação Nacional. Lei No 9.394, de 20 de dezembro de 1996. Disponível em: https://www.planalto.gov.br/ccivil_03/Leis /L9394.htm. Acesso em 22/03/2019.

BRITO Eliana Póvoas P. Estrela. O currículo do Ensino Médio baiano: entre a formação integral e a valorização das diferenças. In: Currículo sem Fronteiras, v. 18, n. 3, p. 1003-1024, set./dez. 2018.

CARNEIRO, Aparecida Sueli. A Construção do Outro como Não-Ser como fundamento do Ser. Tese de Doutorado. Feusp, 2005.

Convenção sobre a Proteção do Patrimônio Mundial Cultural e Natural- 1972.

UNESCO. Disponível em: www.unesco. org.br. Acesso em: 25 de julho de 2009.

FOUCAULT, Michel. A ordem do discurso: aula inaugural no Collège de France, pronunciada em 2 de dezembro de 1970. São Paulo, Loyola, 2003.

FREIRE, Paulo. Por uma Pedagogia da Pergunta / Paulo Freire, Antonio Faundez. - Rio e Janeiro: Paz e Terra, 1985.

GALLO, Sílvio. Deleuze \& a Educação. Belo Horizonte: Autêntica Editora, 2003.

GIL, Carmen e MEINERZ, Carla. Educação, patrimônio cultural e relações étnico-raciais: possibilidades para a decolonização dos saberes. In: Horizontes, v. 35, n. 1, p. 19-34, jan./abr. 2017.

GÓES, Maria da Graça Coutinho. ExVotos, Promessas e Milagres:

um estudo sobre a Igreja Nossa Senhora da Penna. Dissertação de Mestrado apresentado a CPDOC- Fundação Getúlio Vargas, Rio de Janeiro, 2009.

MENDES, Marcos. Devoção e Território: a Irmandade de São Benedito em Cuiabá. Revista Territórios e Fronteiras V.4 N.1 - Jan/Jul, 2011.

MUDIMBE, V. Y. A invenção de África: gnose, filosofia e a ordem do conhecimento. Portugal: Edições Pedago, 2013.

NORA, Pierre. Entre memória e história: a problemática dos lugares. Projeto

História. São Paulo: PUC-SP. N ${ }^{\circ} 10, \mathrm{p}$. 12. 1993.

NOVAIS, Fernando A. In. MONTES, Maria Lúcia; WISSENBACH, Maria Cristina Cortez. História da Vida Privada no Brasil/ coord. geral da coleção Fernando A. Novais. São Paulo: companhia das letras, 1998, vol.3 e 4.

OLIVEIRA, Luiz Fernandes de e CANDAU, Vera Maria Ferrão. Pedagogia decolonial e educação antirracista e intercultural no Brasil. Educação em Revista. Belo Horizonte. V.26 ,n.01, p.1540, abr. 2010.

QUIJANO, Aníbal. Colonialidade do poder, Eurocentrismo e América Latina. Buenos Aires: CLACSO, 2005.

Disponível em: http://biblioteca.clacso. edu.ar/clacso/sur-sur/20100624103322/12 Quijano.pdf. Acesso em: 15/09/2019.

REVISTA CRUZEIRO. Disponível em: http://memoria.bn.br/docreader/DocReader .aspx ?bib=003581. Acesso em 02/09/2019. 
SANTOS, Boaventura de Sousa. Um discurso sobre as ciências. $7^{\mathrm{a}}$.Ed. São Paulo-Cortez, 2010.

SANTOS, Boaventura de Sousa. Pela mão de Alice: o social e o político na pósmodernidade. $14^{\mathrm{a}}$. ed.- São Paulo: Cortez, 2013.

TOFANI, Frederico de Paula.

EREJAKASÓ PIÁNG? As Culturas

Sambaquieira, Aratu, Tupiguarani e Portuguesa e a Produção do Espaço do Extremo Sul da Bahia, Brasil. Tese de doutorado apresentado a UFMG, 2008.

VEIGA-NETO, Alfredo. Foucault e Educação. Belo Horizonte, Autêntica, 2003. 